\title{
Moisturizers for Patients with Atopic Dermatitis: An Overview
}

\author{
Wararat Sirikudta, Kanokvalai Kulthanan, Supenya Varothai and Piyavadee Nuchkull*
}

Department of Dermatology, Siriraj Hospital, Mahidol University, Thailand

\begin{abstract}
Atopic dermatitis is a chronic inflammatory skin condition result from epidermal barrier defect and immune dysfunction. Not only has lesional skin increase $\mathrm{pH}$ and transepidermal water loss but also non-lesional skin Regular use of moisturizers helps maintain skin hydration and improve barrier dysfunction. Active ingredients in moisturizers can be classified into occlusives, humectants, and emollients according to their properties. Agents with anti-inflammatory effects are also added. This review mainly focus on active agents in moisturizers claimed of suitable for atopic skin, in order to provide more information and aid physicians in selecting and giving advice to patients with atopic dermatitis.
\end{abstract}

Keywords: Atopic dermatitis; Moisturizers; Moisturizers with antiinflammatory properties

\section{Introduction}

Atopic dermatitis (AD) is a chronic inflammatory skin condition characterized by xerosis and chronic pruritic eczematous skin lesions. Both genetic and environmental factors contribute to immune dysfunction and epidermal barrier defect in $\mathrm{AD}$ patients [1].

\section{Genetic Factors Affecting Epidermal Barrier}

Normal epidermal barrier is essential in preventing excessive water loss and also protecting skin from external insults such as microbe, chemical and mechanical damage. Abnormalities in gene encoding epidermal structural proteins, stratum corneum proteases and protease inhibitors play a role in epidermal barrier dysfunction.

Filaggrin is a structural protein that aggregate keratin filament and form cornified envelope which strengthen corneocytes. Also, filaggrin are degraded into natural moisturizing factor (NMF) which helps keeping stratum corneum hydrated and maintain acidic skin $\mathrm{pH}$. The component of NMF is including sodium pyrrolidone carboxylic acid (PCA), urocanic acid, alanine, lactate and urea [2,3]. Mutations in filaggrin gene are identified in up to two-thirds of AD patients [4]. Additionally, Loss-of-function mutations in filaggrin gene are risk factors in developing this disease [5].

Stratum corneum proteases and protease inhibitors regulate normal desquamation process of epidermis thus maintaining proper thickness of skin. Whether mutation of gene encoding kallikreinrelated peptidase 7 , a serine protease, is associated with $\mathrm{AD}$ is still debatable [1]. Mutations in serine protease inhibitor Kazal-type 5 gene and cystatin A gene also relate with $\mathrm{AD}[6,7]$.

\section{Environmental Factors Affecting Epidermal Barrier}

Exogenous proteases secreted by house dust mite and Staphylococci cause epidermal barrier breakdown [8]. Use of soap and detergent can increase skin $\mathrm{pH}$, thus enhancing protease activities [1].

\section{Moisturizers for AD Patients}

Not only has atopic lesional skin impaired epidermal barrier, but non-lesional skin also shows defect of barrier function. Atopic xerosis is the subtle dryness of skin adjacent to $\mathrm{AD}$ lesions and has decreased level of ceramide, sebum lipids and amino acid. Additionally, elevation of transepidermal water loss (TEWL), increased skin $\mathrm{pH}$ and shortening of stratum corneum turnover rate are concomitantly present in this area. These changes predispose non-lesional skin to develop AD skin lesion $[9,10]$. Regular use of moisturizers can help improve epidermal barrier defect and lessen progression of atopic xerosis to AD.

Normal epidermis has pro-inflammatory cytokines which help repair epidermal barrier dysfunction. Epidermal barrier defect in patients with $\mathrm{AD}$ results from repeatedly stimulation of inflammatory cascade particularly $\mathrm{T}$ helper- 2 cytokine response and activation of serine pretease ("outside-to-inside" theory of $\mathrm{AD}$ pathogenesis). The use of moisturizers improve barrier function, thus could lessen those inflammation [11].

Moisturizers are topical formulations that help maintain skin hydration by reduce TEWL. Moreover, moisturizers help restore skin barrier, preserve skin integrity and appearance, and repair lipid barrier function [12]. Since epidermal barrier defect plays an essential part in pathogenesis of $\mathrm{AD}$, moisturizers are generally recommended as standard treatment [13-15]. For AD patients, twice daily application of moisturizers with a hydrophilic base helps maintain skin hydration [13]. Besides, use of moisturizers reduces the amount of topical corticosteroids used in infants with $\mathrm{AD}[16]$.

\section{Moisturizers Ingredients}

Active ingredients in moisturizers can be classified into three main classes including occlusives, humectants, and emollients [17].

\section{Occlusives}

Occlusive component helps reduce TEWL by forming an external hydrophobic layer on skin surface. The most pronounced effect can be achieved by applying onto slightly dampened skin. Examples of occlusives are petrolatum, mineral oils, lanolin and silicone derivatives [12]. Petrolatum is commonly used in topical formulations. It is the

*Corresponding author: Piyavadee Nuchkull, Department of Dermatology, Faculty of Medicine Siriraj Hospital, Mahidol University, 2 Prannok Road, Bangkoknoi, Bangkok 10700, Thailand, Tel: 662-419-4334; Fax: 662-411-5031; E-mail: kookkik_ahs@hotmail.com

Received June 25, 2013; Accepted July 25, 2013; Published July 30, 2013

Citation: Sirikudta W, Kulthanan K, Varothai S, Nuchkull P (2013) Moisturizers for Patients with Atopic Dermatitis: An Overview. J Allergy Ther 4: 143. doi:10.4172/2155-6121.1000143

Copyright: @ 2013 Sirikudta W, et al. This is an open-access article distributed under the terms of the Creative Commons Attribution License, which permits unrestricted use, distribution, and reproduction in any medium, provided the original author and source are credited. 
most effective moisturizer as seen from its capacity to reduce TEWL by $99 \%$ [18]. Petrolatum is also able to diffuse into intercellular lipid of stratum corneum and aid in barrier recovery [19]. Nevertheless, the major drawback of petrolatum and most occlusives are their greasy feel. Mineral oils (paraffinum liquidum) provide more favorable texture, but it can reduce TEWL by only $30 \%$. Lanolin or wool alcohol is not frequently used due to its potential allergenicity, unpleasant odor and expense [20]. Silicone derivatives, including dimethicone and cyclomethicone, provide less greasy feel and hypoallergenic, and are frequently used in "oil-free" formulations. The term "oil-free" indicates that neither mineral nor vegetable oils are added in the product [17].

\section{Humectants}

Humectants are compounds with several hydrophilic hydroxyl groups, thus capable of absorbing and holding water. They are able to attract water from dermis into epidermis, and also trapping water from external environment if relative ambient humidity exceeds $70 \%$ [17]. Moisturizers that contain humectants alone can increase TEWL by absorbing and evaporating water from dermis into environment, especially in barrier compromised skin and low ambient humidity. For this reason, humectants are usually combined with occlusive [21]. Ingredients with humectant properties are, for instance, glycerin, lactic acid, propylene glycol, butylene glycol, panthenol, sodium PCA and urea.

Glycerin or glycerol can activate transglutaminase activity in the stratum corneum, enhance corneocytes maturation process and decrease scaling in xerotic skin [12]. Glycerin also has a reservoir effect. To illustrate, the effect of glycerin still persists even though it is no longer detected on the skin. Additionally, glycerin can modify highly conserved water channels in skin, called as aquaporins. Aquaporin-3 is the main aquaporin found in basal and suprabasal layer of epidermis. Increased expression of aquaporin-3 is presented in skin diseases with elevated TEWL [22].

Lactic acid is an alpha hydroxyl acids in which there is hydroxyl group at the alpha position of the carbon chain. It is a composition of NMF at level of about 12\% [2]. Both lactic acid and its salt, sodium lactate, have been shown to increase water holding capacity and extensibility of skin [23].

Propylene glycol and butylene glycol are viscous, colorless liquid with humectant qualities. Propylene glycol is a penetration enhancer so it is usually used as a solvent and vehicle for water-insoluble substances. It has been shown that propylene glycol can cause irritant and contact dermatitis. Butylene glycol is less irritating than propylene glycol. No cross-reaction between these two substances has been reported [23].

Panthenol is a clear, colorless, odorless, viscous liquid. It is converted to D-pantothenic acid (vitamin $\mathrm{B}_{5}$ ) in tissue [23]. Besides its humectant property, panthenol are able to promote fibroblast proliferation and wound healing process [24].

Sodium PCA accounts for $12 \%$ component of NMF and is among the most powerful humectants [2]. Another important humectant is urea, of which $10 \%$ concentration cream has been used in treatment of ichthyosis and hyperkeratotic skin disorders [23]. Urea has been shown to reduce TEWL in AD and ichthyosis patients [25].

\section{Emollients}

Emollients are compounds able to fill the cracks between clusters of desquamating corneocytes. They help improve skin conditioning and consumer satisfactions by giving a smooth, softness and flexibility to the skin surface. Even though emollient properties do not associate with reduction of TEWL, some emollients have occlusive or humectant properties [17]. Emollient alcohols such as cetyl, stearyl, octyl dodecanol, hexyl dodecanol and oleyl alcohol, give a smooth texture to skin. Ester-type emollients are, for examples, oleyl oleate, octyl stearate, isopropyl myristate, stearyl isononanoate, and PEG-7 glyceryl cocoate [20].

Ceramides are the essential component of intercellular lipids in stratum corneum. Ceramides levels in skin of $\mathrm{AD}$ patients are decreased. The use of formulations consist of physiological lipids, including ceramides, cholesterols and free fatty acids, has been revealed to restore skin integrity and function [26]. Additionally, the effects of application of ceramide-dominant, physiological-lipid based formulations were comparable to the use of fluticasone in patients with moderate-tosevere $\mathrm{AD}$ in improvement of disease severity, pruritic symptoms and sleep habits [27].

\section{Anti-inflammatory Agents}

Besides the active ingredients of moisturizers mentioned above, some active ingredients with anti-inflammatory property are also added into moisturizers with claims of being suitable for atopic skin. The use of these anti-inflammatory agents may reduce or substitute for the use of topical corticosteroids, thus minimizing their side effects. Some anti-inflammatory agents added in moisturizers for atopic skin are review here.

\section{Aloe barbadensis leaf powder (Aloe vera)}

The botanical name of Aloe vera is Aloe barbadensis Miller and it belongs to the Liliaceae family. Aloe vera has anti-inflammatory, anti-pruritic, analgesic and wound healing properties [28]. Active ingredients in aloe vera are salicylic acid, magnesium lactate and gel polysaccharides [29]. Previous publication showed two-week application of $0.1,0.25$ and $0.5 \%$ of aloe vera extract could increase skin hydration, though TEWL were not affected [30].

\section{Bisabolol}

Bisabolol can be extracted from German chamomile (Matricaria recutita). It has anti-inflammatory and anti-spasmodic properties in animal studies. Others substances in German chamomile with these properties are sesquiterpene alcohol, chamazulene and flavinoids. The anti-inflammatory effect is attributed to inhibition of cyclooxygenase and lipoxygenase. Furthermore, bisabolol was also thought to promote granulation tissues in wound healing [31]. A randomized, doubleblind clinical study among $278 \mathrm{AD}$ patients showed that an eightweek twice daily application of formulation containing heparin and levomenol ( $a$-bisabolol) were able to significantly improve pruritus and disease symptoms. Use of a single agent could also alleviate itching and inflamed skin, though the combination of these two agents showed higher efficacy [32].

\section{Butyrospermum parkii (Shea butter)}

Shea butter is the fat derived from the kernels of Vitellaria paradoxa Gaertner (Sapotaceae), which is previously known as Butyrospermum parkii. Five major fatty acids, including palmitic, stearic, oleic, linoleic, and arachidic acids, are the composition of shea butter. Of which, steric and oleic acids account for $85-90 \%$ [33]. In addition, triterpene acetate and cinnamate esters found in shea butter were shown to have antiinflammatory and anti-tumor promoting effects [34]. 
Citation: Sirikudta W, Kulthanan K, Varothai S, Nuchkull P (2013) Moisturizers for Patients with Atopic Dermatitis: An Overview. J Allergy Ther 4: 143. doi:10.4172/2155-6121.1000143

Page 3 of 6

\section{Glycyrrhetinic acid}

Glycyrrhetinic acid is a triterpenoid compound extracted from licorice root. It has anti-inflammatory, antiviral and antitumor effects. Previous studies revealed that glycyrrhetinic acid can reduce inflammation by suppress expression of surface markers and inflammatory mediators of lipopolysaccharide-stimulated mature dendritic cells [35].

\section{Glycyrrhiza inflata/Licochalcone A}

Glycyrrhiza inflata can be extracted from licorice root. Licochalcone

\begin{tabular}{|c|c|c|c|c|c|c|c|c|c|c|c|c|}
\hline \multirow[t]{2}{*}{ Active ingredients } & \multicolumn{12}{|c|}{ Product } \\
\hline & A & B & C & D & $E$ & $\mathbf{F}$ & G & $\mathbf{H}$ & I & $\mathbf{J}$ & $\mathrm{K}$ & $\mathbf{L}$ \\
\hline Arachidyl alcohol & & & & $x$ & & & & & & & & \\
\hline Behenyl alcohol & & & & $x$ & $x$ & & & & & & & \\
\hline Betaine & & & & & & & & & & & $x$ & \\
\hline Butylene glycol & & & & $x$ & & & & & & & & \\
\hline Caprylic/Capric triglyceride & $x$ & $x$ & $x$ & & $x$ & $x$ & $x$ & & & & & $x$ \\
\hline Ceramide 3 & & & & & & & $x$ & $x$ & & & & $x$ \\
\hline Cetearyl alcohol & & & $x$ & & $x$ & & $x$ & & $x$ & & & \\
\hline Cyclomethicone & & & & & & & $x$ & & & & & \\
\hline Cyclopentasiloxane & & & & & $x$ & & & & & $x$ & & \\
\hline Dimethicone & $x$ & $x$ & $x$ & & $x$ & $x$ & $x$ & $x$ & $x$ & $x$ & & \\
\hline Ethylhexyl palmitate & & $x$ & & $x$ & & & & & & & & \\
\hline Glycerin & $x$ & $x$ & $x$ & $x$ & $x$ & $x$ & $x$ & $x$ & $x$ & $x$ & $\mathrm{x}$ & $x$ \\
\hline Glyceryl stearate & $\mathrm{x}$ & & $x$ & $x$ & $x$ & & & & & & & \\
\hline Helianthus annuus (sunflower) seed oil & & & & & $\mathrm{X}$ & & & & & & & \\
\hline Hydrogenated castor oil & & & & & & $x$ & & $\mathrm{X}$ & & & & \\
\hline Hydrogenated polydecene & & & & & & & & & $x$ & & & \\
\hline Isohexadecane & & $x$ & & & & & & & & & & \\
\hline Isopropyl palmitate & & & & & & $x$ & & & & & & \\
\hline Lactic acid & & & & & & $x$ & $\mathrm{x}$ & & & & & \\
\hline Mannitol & $\mathrm{x}$ & $\mathrm{x}$ & & & & & $x$ & & & & & \\
\hline Mineral oil (Paraffinum liquidum) & $\mathrm{x}$ & $\mathrm{X}$ & & & & $x$ & & $\mathrm{X}$ & & $\mathrm{x}$ & & \\
\hline Myreth-3 myristate & $\mathrm{x}$ & & & & & & & & & & & \\
\hline Octyldodecanol & & & & & & $x$ & $x$ & & & & & \\
\hline Olea europaea & & & $x$ & & & & & & & & $x$ & $x$ \\
\hline Oleic/Linoleic triglyceride & & & & & & & & & $x$ & & & \\
\hline Palm glycerides & & & & & & & & & & & $x$ & \\
\hline Panthenol & & & & & $\mathrm{X}$ & $x$ & & & & & & \\
\hline Saccharide isomerate & & & & & & & & & $x$ & & & \\
\hline Sodium lactate & & & & & & $\mathrm{x}$ & $x$ & & & & & \\
\hline Sodium PCA & & & & & $x$ & & $\mathrm{x}$ & & & & & \\
\hline Sorbital & & & & & $x$ & & & & & & & \\
\hline Squalane & & & & & & & & & & & $x$ & $x$ \\
\hline Stearic acid & $x$ & & $x$ & & & & & & & $x$ & & \\
\hline Sucrose & & & & & & & $\mathrm{x}$ & & & $\mathrm{x}$ & & \\
\hline Urea & & & & & & $x$ & $x$ & & & & & \\
\hline \multicolumn{13}{|l|}{$\begin{array}{l}\text { Active ingredient with anti-inflammatory } \\
\text { effect }\end{array}$} \\
\hline Aloe barbadensis leaf powder (Aloe vera) & & & & & & & & & & & & $x$ \\
\hline Bisabolol & & & & $x$ & & $x$ & & & & & & \\
\hline Butyrospermum parkii (Shea butter) & & & & $x$ & $x$ & & & & & $x$ & & $\mathrm{x}$ \\
\hline Glycyrrhetinic acid & & & & $\mathrm{x}$ & & & & & & & & \\
\hline Glycyrrhiza inflata & & & & & & & & $x$ & & & & \\
\hline Licochalcone A & & & & & & & & $\mathrm{X}$ & & & & \\
\hline Niacinamide & & $\mathrm{x}$ & & & $x$ & & & & & $x$ & & \\
\hline Palmitoylethanolamide & & & & & & & & & & & $x$ & \\
\hline Stimu-tex®AS & & & & & & & & & $x$ & & & \\
\hline Vitis vinifera & & & $x$ & $x$ & & & & $x$ & & & & \\
\hline Zinc gluconate & $x$ & & & & & & & & & & & \\
\hline
\end{tabular}

A: Atoderm PO cream (Bioderma laboratoire dermatologique, France); B: Atoderm PP cream (Bioderma laboratoire dermatologique, France); C: Atopalm intensive moisturizing cream (NeoPharm, Korea); D: Atopiclair cream/lotion (Sinclair Pharma Sri, Italy); E: Cetaphil Restoraderm cream (Galderma, Canada); F: Eucerin 3\% urea cream (Beiersdorf AG, Germany); G: Eucerin 5\% urea cream (Beiersdorf AG, Germany); H: Eucerin soothing lotion 12\% omega (Beiersdorf AG, Germany); I: Ezerra cream (HOE Pharmaceuticals, Thailand); J: La Roche-Posay Lipikar cream (La Roche-Posay, France); K: Physiogel Al cream [stiefel laboratories (ireland)]; L: Zermix cream (Pure skin, Thailand)

Table 1: Active ingredients in moisturizers for atopic skin. 
A is the main component of glycyrrhiza inflata. Licochalcone A has been shown to inhibit $\mathrm{T}$ cell proliferation and production of inflammatory cytokine [36]. Other parts of glycyrrhiza inflata are licochalcone B, licochalcone $\mathrm{C}$, licochalcone $\mathrm{D}$, echinatin and isoliquiritigenin. Among these, licochalcone $\mathrm{B}$ and $\mathrm{D}$ were found to have anti-inflammatory effects [37].

Previous study among children with mild to moderate $\mathrm{AD}$ demonstrated that twice daily application of formulation containing licochalcone A was comparable to the use of hydrocortisone lotion in improvement of symptoms. Moreover, the licochalcone-treated site showed less relapse than another site, though no significant difference was found [38]. Interestingly, a randomized half-head study among patients with inflamed scalp conditions showed that a leave-on tonic containing urea, lactate, polidocanol, and glycyrrhiza inflata root extract, containing licochalcone A could alleviate dryness, pruritus and also reduce inflammation [39].

\section{Niacinamide}

Niacinamide, also known as nicotinamide or vitamin $\mathrm{B}_{3}$ is able to improve skin barrier functions by increase ceramides and other

\begin{tabular}{|c|c|c|c|}
\hline \multirow[t]{2}{*}{ Active ingredients } & \multicolumn{3}{|c|}{ Properties } \\
\hline & Occlusive & Humectant & Emollient \\
\hline Arachidyl alcohol & & & $x$ \\
\hline Behenyl alcohol & & & $x$ \\
\hline Betaine & & $x$ & \\
\hline Butylene glycol & & $\mathrm{X}$ & \\
\hline Caprylic/Capric triglyceride & $x$ & & \\
\hline \multicolumn{4}{|l|}{ Ceramide 3} \\
\hline Cetearyl alcohol & & & $x$ \\
\hline Cyclomethicone & $x$ & & $x$ \\
\hline Cyclopentasiloxane & & & $x$ \\
\hline Dimethicone & $x$ & & $x$ \\
\hline Ethylhexyl palmitate & & & $\mathrm{x}$ \\
\hline Glycerin & & $\mathrm{X}$ & \\
\hline Glyceryl stearate & $x$ & & $\mathrm{x}$ \\
\hline $\begin{array}{l}\text { Helianthus annuus (sunflower) } \\
\text { seed oil }\end{array}$ & & & $x$ \\
\hline Hydrogenated castor oil & & & $x$ \\
\hline Hydrogenated polydecene & & & $x$ \\
\hline Isohexadecane & & & $x$ \\
\hline Isopropyl palmitate & & & $x$ \\
\hline Lactic acid & & $x$ & \\
\hline Mannitol & & $x$ & \\
\hline Mineral oil (Paraffinum liquidum) & $x$ & & \\
\hline Myreth-3 myristate & & & $x$ \\
\hline Octyldodecanol & & & $x$ \\
\hline Olea europaea & & & $x$ \\
\hline Oleic/Linoleic triglyceride & & & $x$ \\
\hline Palm glycerides & & & $x$ \\
\hline Panthenol & & $\mathrm{X}$ & \\
\hline Saccharide isomerate & & $\mathrm{X}$ & \\
\hline Sodium lactate & & $x$ & \\
\hline Sodium PCA & & $x$ & \\
\hline Sorbital & & $x$ & \\
\hline Squalane & $x$ & & \\
\hline Stearic acid & $x$ & & \\
\hline Sucrose & & $\mathrm{X}$ & \\
\hline Urea & & $x$ & \\
\hline
\end{tabular}

Table 2: Moisturizing properties of active ingredients in moisturizers for atopic skin. intercellular lipids levels in epidermis, and promote upregulation of serine palmitoyltransferase [40]. Moreover, twice daily application of formula containing niacinamide on tape-stripping skin revealed that niacinamide could reduce inflammation, decrease TEWL and increase stratum corneum thickness [41]. Niacinamide was shown to significantly decrease TEWL in atopic dry skin compare with white petrolatum [42]. In randomized, controlled, comparative studies of the stratum corneum integrity, moisturizers containing niacinamide yielded more rapid and sustained improvement of dryness and stratum corneum barrier than conventional moisturizers [43].

\section{Palmitoylethanolamide (PEA)}

PEA is an endogenous lipid that mimic stratum corneum components [44]. PEA belongs to fatty-acid $\mathrm{N}$-acylethanolamine family, which functions as peroxisome proliferators-activated receptor $\alpha$ agonist. Thus, PEA has both anti-inflammatory and analgesic effects [45]. A large multinational, multicenter study among 2,456 AD patients with mild to moderate severity demonstrated that product containing PEA could alleviate pruritus, dryness and eczema lesion. Furthermore, $56 \%$ of patients were able to discontinue topical corticosteroids used [46].

\section{Spent grain wax, Butyrospermum parkii (shea butter) extract and Argania spinosa kernel oil}

Products consisting of spent grain wax, butyrospermum parkii (shea butter) extract and Argania spinosa kernel oil are claimed of soothing dry and irritated skin. Moreover, manufacturers provide that they also have anti-pruritus and anti-inflammatory qualities. However, no reports about its efficacy have been published so far.

\section{Vitis vinifera}

Vitis vinifera, or grape seed extract, has both anti-inflammatory and antioxidant properties [47]. Studies regarding the use of formulation containing glycyrrhetinic acid, telmesteine and Vitis vinifera extracts in mild to moderate $\mathrm{AD}$ patients showed that it improve pruritic symptoms, and also can be used as single agents for the treatment of symptoms [48-50].

\section{Zinc gluconate}

Zinc gluconate, also called zincum gluconicum, is the zinc salt of gluconic acid. It has been shown to be efficient to treat inflammatory skin diseases such as acne vulgaris. Recent studies revealed that its antiinflammatory effects may target at peroxisome proliferator-activated receptors- $\alpha$ (PPARs- $\alpha$ ), human $\beta$-defensin-2, and psoriasin [51,52] .

\section{Conclusions}

Since moisturizers are essential part in treatment of $\mathrm{AD}$ and the key in restoring epidermal barrier defects, this review explores active ingredients added in moisturizers with claims of being suitable for atopic skin as shown in Table 1. All ingredients are obtained from ingredient labeling on the products in which the ingredients are listed in descending order of predominance. Anti-inflammatory agents, common active ingredients, and main constituents are focused upon here and properties of these agents are summarized in Table 2. This review hopes to provide more information and aid physicians in selecting treatments and giving advice to their patients.

\section{References}

1. Cork MJ, Danby SG, Vasilopoulos Y, Hadgraft J, Lane ME, et al. (2009) Epidermal barrier dysfunction in atopic dermatitis. J Invest Dermatol 129: 1892-1908. 
Citation: Sirikudta W, Kulthanan K, Varothai S, Nuchkull P (2013) Moisturizers for Patients with Atopic Dermatitis: An Overview. J Allergy Ther 4: 143. doi:10.4172/2155-6121.1000143

Page 5 of 6

2. Lodén M (2003) Role of topical emollients and moisturizers in the treatment of dry skin barrier disorders. Am J Clin Dermatol 4: 771-788.

3. Wolf R, Wolf $D$ (2012) Abnormal epidermal barrier in the pathogenesis of atopic dermatitis. Clin Dermatol 30: 329-334.

4. Irvine AD (2007) Fleshing out filaggrin phenotypes. J Invest Dermatol 127: 504507

5. van den Oord RA, Sheikh A (2009) Filaggrin gene defects and risk of developing allergic sensitisation and allergic disorders: systematic review and meta-analysis. BMJ 339: b2433.

6. Nishio Y, Noguchi E, Shibasaki M, Kamioka M, Ichikawa E, et al. (2003) Association between polymorphisms in the SPINK5 gene and atopic dermatitis in the Japanese. Genes Immun 4: 515-517.

7. Lee YA, Wahn U, Kehrt R, Tarani L, Businco L, et al. (2000)A major susceptibility locus for atopic dermatitis maps to chromosome 3q21. Nat Genet 26: 470-473.

8. Jeong SK, Kim HJ, Youm JK, Ahn SK, Choi EH, et al. (2008) Mite and cockroach allergens activate protease-activated receptor 2 and delay epidermal permeability barrier recovery. J Invest Dermatol 128: 1930-1939.

9. Tagami H, Kobayashi H, O'Goshi K, Kikuchi K (2006)Atopic xerosis: employment of noninvasive biophysical instrumentation for the functional analyses of the mildly abnormal stratum corneum and for the efficacy assessment of skin care products. J Cosmet Dermatol 5: 140-149.

10. Watanabe M, Tagami H, Horii I, Takahashi M, Kligman AM (1991) Functiona analyses of the superficial stratum corneum in atopic xerosis. Arch Dermatol 127: $1689-1692$

11. Elias PM, Wakefield JS (2011) Therapeutic implications of a barrier-based pathogenesis of atopic dermatitis. Clin Rev Allergy Immunol 41: 282-295.

12. Anderson PC, Dinulos JG (2009) Are the new moisturizers more effective? Curr Opin Pediatr 21: 486-490

13. Darsow U, Wollenberg A, Simon D, Taïeb A, Werfel T, et al. (2010) ETFAD/ EADV eczema task force 2009 position paper on diagnosis and treatment of atopic dermatitis. J Eur Acad Dermatol Venereol 24: 317-328.

14. Saeki H, Furue M, Furukawa F, Hide M, Ohtsuki M, et al. (2009) Guidelines for management of atopic dermatitis. J Dermatol 36: 563-577.

15. Akdis CA, Akdis M, Bieber T, Bindslev-Jensen C, Boguniewicz M, et al. (2006) Diagnosis and treatment of atopic dermatitis in children and adults: European Academy of Allergology and Clinical Immunology/American Academy of Allergy, Asthma and Immunology/PRACTALL Consensus Report. Allergy 61: 969-987.

16. Grimalt R, Mengeaud V, Cambazard F; Study Investigators' Group (2007) The steroid-sparing effect of an emollient therapy in infants with atopic dermatitis: a randomized controlled study. Dermatology 214: 61-67.

17. Del Rosso JQ (2009) Moisturizers: Function, formulation and clinical applications. In: Draelos ZD, editor. Cosmeceuticals. Procedures in Cosmetic Dermatology ( $2^{\text {nd }}$ edn): 97-102.

18. Lodén M (2005) The clinical benefit of moisturizers. J Eur Acad Dermato Venereol 19: 672-688.

19. Ghadially R, Halkier-Sorensen L, Elias PM (1992) Effects of petrolatum on stratum corneum structure and function. J Am Acad Dermatol 26: 387-396.

20. Flynn TC, Petros J, Clark RE, Viehman GE (2001) Dry skin and moisturizers. Clin Dermatol 19: 387-392.

21. Nolan K, Marmur E (2012) Moisturizers: reality and the skin benefits. Dermatol Ther 25: 229-233.

22. Draelos ZD (2010) Active agents in common skin care products. Plast Reconstr Surg 125: 719-724.

23. Loden M (2006) Hydrating substances. In: Paye M, Barel AO, Maibach $\mathrm{HI}$ editors. Handbook of Cosmetic Science and Technology: CRC Press: 265-280.

24. McDaniel DH, DiNardo J, Lewis J (2006) The Role of Cosmeceuticals in Dermatology. In: Draelos ZD, Thaman LA, editors. Cosmetic Formulation of Skin Care Products. New York: Taylor and Francis Group: 187-203.

25. Lodén M, Andersson AC, Lindberg M (1999) Improvement in skin barrier function in patients with atopic dermatitis after treatment with a moisturizing cream (Canoderm). Br J Dermatol 140: 264-267.
26. Coderch L, López O, de la Maza A, Parra JL (2003) Ceramides and skin function. Am J Clin Dermatol 4: 107-129.

27. Sugarman JL, Parish LC (2009) Efficacy of a lipid-based barrier repair formulation in moderate-to-severe pediatric atopic dermatitis. J Drugs Dermatol 8: 1106-1111.

28. Feily A, Namazi MR (2009) Aloe vera in dermatology: a brief review. G Ital Dermatol Venereol 144: 85-91.

29. Bedi MK, Shenefelt PD (2002) Herbal therapy in dermatology. Arch Dermatol 138: 232-242.

30. Dal'Belo SE, Gaspar LR, Maia Campos PM (2006) Moisturizing effect of cosmetic formulations containing Aloe vera extract in different concentrations assessed by skin bioengineering techniques. Skin Res Technol 12: 241-246.

31. Shenefelt PD (2011) Herbal Treatment for Dermatologic Disorders. In: Benzie IFF, Wachtel-Galor S, editors. Herbal Medicine: Biomolecular and Clinical Aspects ( $2^{\text {nd }}$ edn) Boca Raton (FL)

32. Arenberger $P$, Arenbergerová $M$, Drozenová $H$, Hladíková $M$, Holcová S (2011) Effect of topical heparin and levomenol on atopic dermatitis: a randomized four-arm, placebo-controlled, double-blind clinical study. J Eur Acad Dermatol Venereol 25: 688-694.

33. Goreja WG (2004) Shea Butter: The Nourishing Properties of Africa's Best-Kept Natural Beauty Secret. New York: Amazing Herb Press.

34. Akihisa T, Kojima N, Kikuchi T, Yasukawa K, Tokuda H, et al. (2010) Antiinflammatory and chemopreventive effects of triterpene cinnamates and acetates from shea fat. J Oleo Sci 59: 273-280.

35. Kim ME, Kim HK, Kim DH, Yoon JH, Lee JS (2013) 18î-Glycyrrhetinic acid from licorice root impairs dendritic cells maturation and Th1 immune responses. Immunopharmacol Immunotoxicol 35: 329-335.

36. Kolbe L, Immeyer J, Batzer J, Wensorra U, tom Dieck K, et al. (2006) Antiinflammatory efficacy of Licochalcone A: correlation of clinical potency and in vitro effects. Arch Dermatol Res 298: 23-30.

37. Furusawa J, Funakoshi-Tago M, Mashino T, Tago $\mathrm{K}$, Inoue $\mathrm{H}$, et al (2009) Glycyrrhiza inflata-derived chalcones, Licochalcone A, Licochalcone B and Licochalcone D, inhibit phosphorylation of NF-kappaB p65 in LPS signaling pathway. Int Immunopharmacol 9: 499-507.

38. Udompataikul M, Srisatwaja W (2011) Comparative trial of moisturize containing licochalcone A vs. hydrocortisone lotion in the treatment of childhood atopic dermatitis: a pilot study. J Eur Acad Dermatol Venereol 25: 660-665.

39. Schweiger D, Baufeld C, Drescher P, Oltrogge B, Höpfner S, et al. (2013) Efficacy of a new tonic containing urea, lactate, polidocanol, and glycyrrhiza inflata root extract in the treatment of a dry, itchy, and subclinically inflamed scalp. Skin Pharmacol Physiol 26: 108-118.

40. Tanno O, Ota Y, Kitamura N, Katsube T, Inoue S (2000) Nicotinamide increases biosynthesis of ceramides as well as other stratum corneum lipids to improve the epidermal permeability barrier. Br J Dermatol 143: 524-531.

41. Mohammed D, Crowther JM, Matts PJ, Hadgraft J, Lane ME (2013) Influence of niacinamide containing formulations on the molecular and biophysical properties of the stratum corneum. Int J Pharm 441: 192-201.

42. Soma Y, Kashima M, Imaizumi A, Takahama H, Kawakami T, et al. (2005) Moisturizing effects of topical nicotinamide on atopic dry skin. Int J Dermato 44: 197-202.

43. Christman JC, Fix DK, Lucus SC, Watson D, Desmier E, et al. (2012) Two randomized, controlled, comparative studies of the stratum corneum integrity benefits of two cosmetic niacinamide/glycerin body moisturizers vs conventional body moisturizers. J Drugs Dermatol 11: 22-29.

44. Kircik L (2010) A nonsteroidal lamellar matrix cream containing palmitoylethanolamide for the treatment of atopic dermatitis. J Drugs Dermato 9: 334-338.

45. D'Agostino G, La Rana G, Russo R, Sasso O, lacono A, et al. (2009) Centra administration of palmitoylethanolamide reduces hyperalgesia in mice via inhibition of NF-kappaB nuclear signalling in dorsal root ganglia. Eur $J$ Pharmacol 613: 54-59.

46. Eberlein B, Eicke C, Reinhardt HW, Ring J (2008) Adjuvant treatment of atopic eczema: assessment of an emollient containing $\mathrm{N}$-palmitoylethanolamine (ATOPA study). J Eur Acad Dermatol Venereol 22: 73-82. 
Citation: Sirikudta W, Kulthanan K, Varothai S, Nuchkull P (2013) Moisturizers for Patients with Atopic Dermatitis: An Overview. J Allergy Ther 4: 143. doi:10.4172/2155-6121.1000143

Page 6 of 6

47. Hemmati AA, Aghel N, Rashidi I, Gholampur-Aghdami A (2011) Topical grape (Vitis vinifera) seed extract promotes repair of full thickness wound in rabbit. In Wound J 8: 514-520.

48. Veraldi S, De Micheli P, Schianchi R, Lunardon L (2009) Treatment of pruritus in mild-to-moderate atopic dermatitis with a topical non-steroidal agent. J Drugs Dermatol 8: 537-539.

49. Boguniewicz M, Zeichner JA, Eichenfield LF, Hebert AA, Jarratt M, et al. (2008) MAS063DP is effective monotherapy for mild to moderate atopic dermatitis in infants and children: a multicenter, randomized, vehicle-controlled study. J Pediatr 152: 854-859.
50. Patrizi A, Raone B, Neri I (2009) Atopiclair. Expert Opin Pharmacother 10: 1223-1230.

51. Poiraud C, Quereux G, Knol AC, Zuliani T, Allix R, et al. (2012) Human $\hat{I}^{2}{ }_{-}$ defensin-2 and psoriasin, two new innate immunity targets of zinc gluconate. Eur J Dermatol 22: 634-639.

52. Poiraud C, Quereux G, Knol AC, Allix R, Khammari A, et al. (2012) Zinc gluconate is an agonist of peroxisome proliferator-activated receptor-l̂t in the epidermis. Exp Dermatol 21: 347-351.
This article was originally published in a special issue, Skin Allergy handled by Editor. Dr. Anton B Alexandroff, Leicester Royal Infirmary, UK 